\title{
Innovative application of a thoracotomy approach to treat saphenous vein graft aneurysm
}

\author{
Ming Guo, MD, and Marc Ruel, MD, MPH
}

From the Division of Cardiac Surgery, University of Ottawa Heart Institute, Ottawa, Ontario, Canada.

Disclosures: Authors have nothing to disclose with regard to commercial support.

Received for publication Sept 16, 2016; accepted for publication Sept 19, 2016; available ahead of print Nov 3, 2016.

Address for reprints: Marc Ruel, MD, MPH, FRCSC, FAHA, University of Ottawa Heart Institute, 3402-40

Ruskin St, Ottawa, Ontario K1Y 4W7, Canada (E-mail: mruel@ottawaheart.ca).

J Thorac Cardiovasc Surg 2017;153:e5-6

$0022-5223 / \$ 36.00$

Copyright (C) 2016 by The American Association for Thoracic Surgery

http://dx.doi.org/10.1016/j.jtcvs.2016.09.047

A saphenous vein graft (SVG) aneurysm is a rare phenomenon after coronary artery bypass grafting. Even though SVG aneurysms commonly are seen as incidental findings on imaging, they can lead to clinical compromise in cases of rupture, fistula formation, or compression of adjacent structures. $^{2-4}$

In this issue of the Journal, Chiu and colleagues ${ }^{5}$ have reported on a progressively growing giant SVG aneurysm that caused compression of the left lingular bronchus and led to dyspnea. Chiu and colleagues ${ }^{5}$ proceeded with resection of the SVG aneurysm as well as patch occlusion

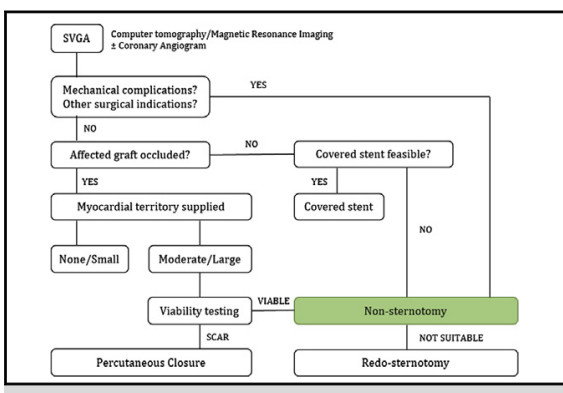

Updated algorithm for vein graft aneurysm (with permission from Ramirez and colleagues ${ }^{1}$ ).

\section{Central Message}

Nonsternotomy approaches can be used to treat a saphenous vein graft aneurysm surgically and should be considered when conservative management or percutaneous intervention is not suitable.

See Article page e1. of the proximal and distal limb of the SVG through a left anterior thoracotomy.

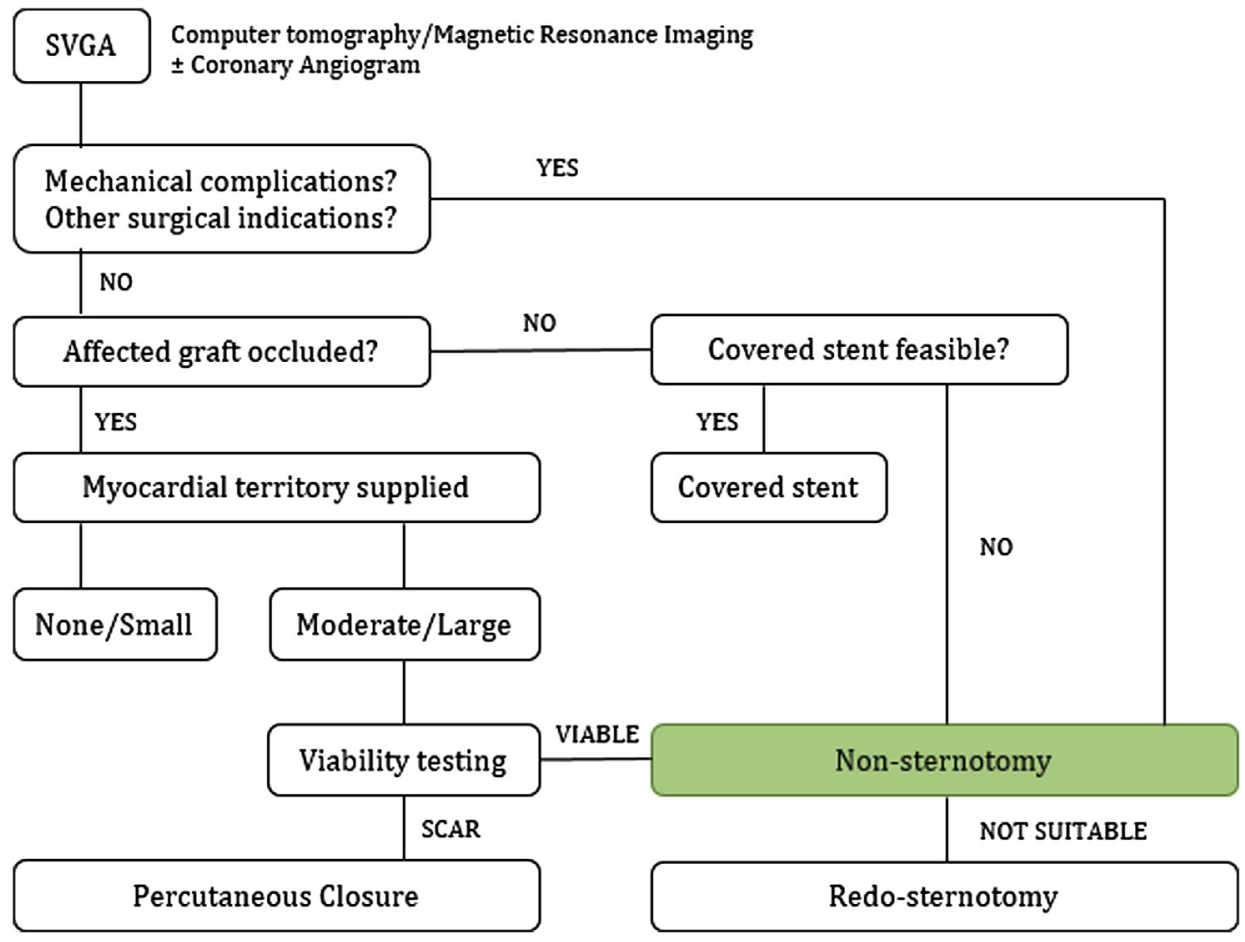

FIGURE 1. Updated algorithm for vein graft aneurysm. Reprinted with permission from: Ramirez FD, Hibbert B, Simard T, Pourdjabbar A, Wilson KR, Hibbert R, et al. Natural history and management of aortocoronary saphenous vein graft aneurysms: a systematic review of published cases. Circulation. 2012;126:2248-56. 
In a systematic review on the natural history and management of SVG aneurysm, our group reported mortalities for SVG aneurysm cases of $13.9 \%$ with surgical resection, $6.1 \%$ with percutaneous intervention, and $23.8 \%$ with conservative management. Furthermore, it has been difficult to establish an appropriate aneurysm size at which intervention should be performed, because adverse outcomes may occur in both small and large aneurysms. Percutaneous interventions, such as covered stents, Amplatzer occluder, or coil embolization may not be beneficial if the patient has symptoms caused by compression by the SVG aneurysm. In some cases, the only suitable option is surgery, which carries a significant risk because of the resternotomy and likely patent grafts. ${ }^{1}$

The novel use of thoracotomy for surgical management of the SVG aneurysm in this case represents an innovative application of a well-studied technique. ${ }^{6}$ Concerns regarding minimally invasive direct coronary bypass through a thoracotomy typically are related to the use of peripheral cannulation or, in the case of off-pump bypass surgery, to the need for high technical skills. The thoracotomy use in this case was a wise choice, both because there was no need for cardiopulmonary bypass or revascularization and because thoracotomy may carry a lower mortality than standard resternotomy in reoperations. ${ }^{7}$

On the other hand, in this case Chiu and colleagues ${ }^{5}$ performed the surgery through a left anterolateral thoracotomy, which appeared considerable in size as depicted in panel C of their article's Figure 2. In the literature, anterolateral thoracotomy has mostly been used for minimally invasive coronary artery bypass grafting that requires take down of the left or right internal thoracic artery as well as anasto- mosis to the left anterior descending artery and all other vessels. If the circumflex territory is the only area of concern, it is typically approached through a lateral or posterolateral thoracotomy. ${ }^{7}$ We wonder whether the surgical exposure might have been improved and incision size minimized in this case by the use of a posterior minithoracotomy, given that the SVG with the aneurysmal dilatation had been initially grafted to an obtuse marginal artery.

In conclusion, nonsternotomy approaches should be considered in cases of SVG aneurysm that require surgical intervention. The position of the thoracotomy depends on the coronary territory of concern, according to the need for revascularization and the localization of the SVG aneurysm (Figure 1).

\section{References}

1. Ramirez FD, Hibbert B, Simard T, Pourdjabbar A, Wilson KR, Hibbert R, et al. Natural history and management of aortocoronary saphenous vein graft aneurysms: a systematic review of published cases. Circulation. 2012;126: 2248-56.

2. Taguchi E, Sawamura T, Kamio T, Fukunaga T, Oe Y, Miyamoto S, et al. An autopsy case of the rupture of a giant aneurysm in a saphenous vein graft: 18 years after CABG. J Cardiol Cases. 2010;2:e88-91.

3. Sugimoto T, Yamamoto K, Yoshii S, Shimada K, Katsu M, Iida Y, et al. Large saphenous vein graft aneurysm with a fistula to the right atrium. Ann Thorac Cardiovasc Surg. 2006;12:435-7.

4. Garcia-Lara J, Pinar-Bermudez E, Hurtado JA, Valdez-Chavarri M. Giant true saphenous vein graft aneurysm. J Am Coll Cardiol. 2009;54:1899.

5. Chiu P, Palmon I, Fischbein M. Giant saphenous vein graft aneurysm compressing the lingular bronchus. J Thorac Cardiovasc Surg. 2017;153:e1-3.

6. McGinn JT Jr, Usman S, Lapierre H, Pothula VR, Mesana TG, Ruel M. Minimally invasive coronary artery bypass grafting: dual-center experience in 450 consecutive patients. Circulation. 2009;120(11 Suppl):S78-84.

7. Dewey TM, Magee M, Edgerton J, Vela R, Prince SL, Acuff T, et al. Left mini-thoracotomy for beating heart bypass grafting: a safe alternative to high-risk intervention for selected grafting of the circumflex artery distribution. Circulation. 2001;104(12 Suppl 1):I99-101. 